\title{
Knowledge of and attitudes towards periodontal health among adults in Tehran
}

\author{
M. Gholami, ${ }^{1,2}$ A. Pakdaman, ${ }^{7}$ A. Jafari ${ }^{1}$ and J.I. Virtanen ${ }^{3}$
}

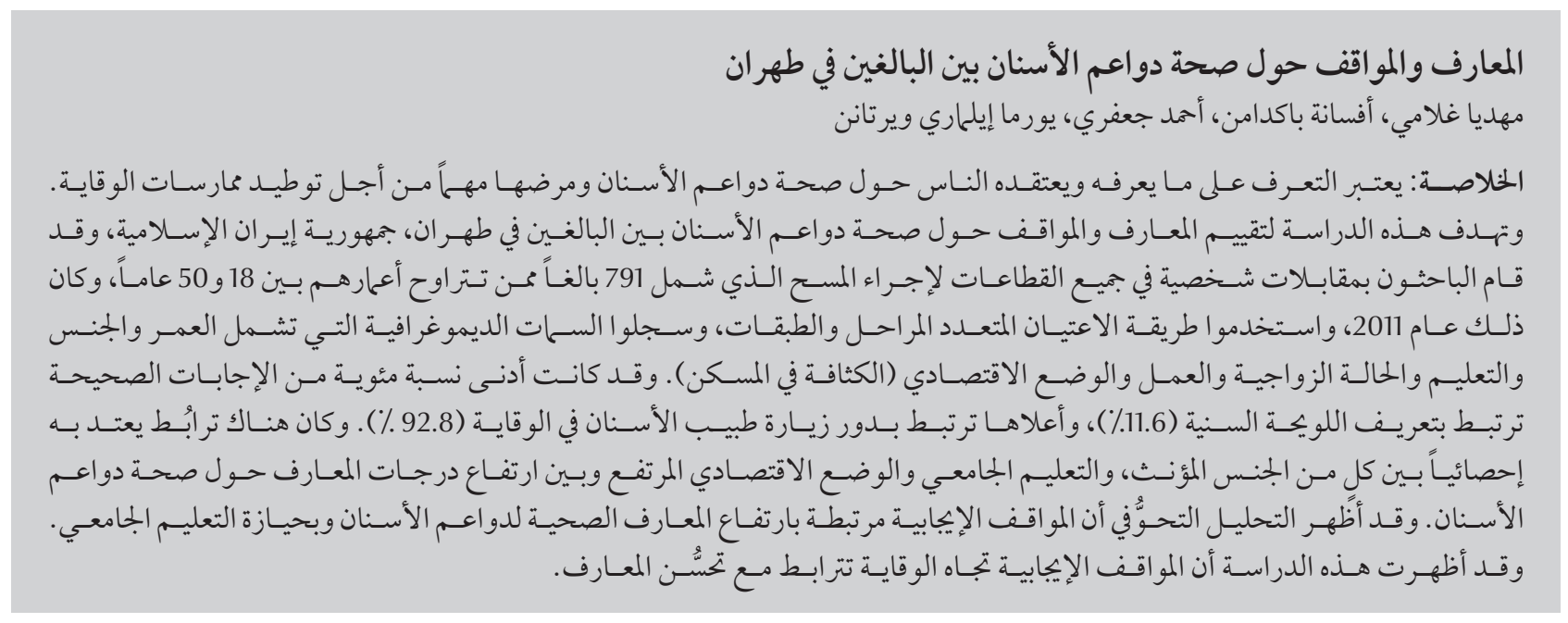

ABSTRACT Determining what people know and believe about periodontal health and disease is important in order to establish prevention practices. This study aimed to assess knowledge of and attitudes towards periodontal health among adults in Tehran, Islamic Republic of Iran. We conducted a cross-sectional face-to-face interview survey in 2011 of 791 adults aged 18-50 years using a stratified, multistage sampling method. We recorded demographic characteristics including age, sex, education, marital status, employment and economic status (housing density). The lowest percentage of correct answers was related to the definition of dental plaque (11.6\%) and the highest was for the role of the dental visit in prevention (92.8\%). Female sex, university education and higher economic status were significantly associated with a higher mean score on periodontal health knowledge. The regression analysis showed that positive attitudes were associated with higher periodontal health knowledge and having university education. In this study positive attitudes towards prevention were related to better knowledge.

\section{Connaissances et attitudes vis-à-vis de la santé parodontale chez des adultes à Téhéran}

RÉSUMÉ La détermination des connaissances et des croyances en matière de santé parodontale et de parodontopathies est essentielle pour établir des pratiques préventives. La présente étude visait à évaluer les connaissances et les attitudes vis-à-vis de la santé parodontale des adultes à Téhéran (République islamique d'Iran). Nous avons mené une enquête transversale reposant sur des entretiens individuels en 2011 auprès de 791 adultes âgés de 18 à 50 ans selon une méthode d'échantillonnage stratifié à plusieurs degrés. Nous avons enregistré les caractéristiques démographiques telles que l'âge, le sexe, le niveau d'études, la situation matrimoniale, l'emploi et le statut économique (la densité du logement). Le pourcentage le plus faible de bonnes réponses était lié à la définition de la plaque dentaire $(11,6 \%)$ alors que le pourcentage le plus élevé était lié au rôle de la visite préventive chez le dentiste (92,8\%). Le fait d'être de sexe féminin, d'avoir un niveau d'études supérieures et un statut économique plus élevé était significativement associé à un score moyen supérieur pour les connaissances en santé parodontale. L'analyse de régression a révélé que les attitudes positives étaient associées à des connaissances en santé parodontale plus élevés et au fait d'avoir suivi des études universitaires. Dans la présente étude, les attitudes positives vis-à-vis de la prévention étaient liées à de meilleures connaissances.

'Department of Community Oral Health, School of Dentistry, Tehran University of Medical Sciences, Islamic Republic of Iran (Correspondence to A.Pakdaman:pakdaman@sina.tums.ac.ir). ${ }^{2}$ Department of Oral Public Health, Institute of Dentistry, University of Helsinki, Helsinki, Finland. IInstitute of Dentistry, University of Oulu; Oulu University Hospital, Oulu, Finland.

Received: 28/01/13; accepted: 13/08/13 


\section{Introduction}

Periodontal diseases including gingivitis and periodontitis are prevalent in all populations worldwide. Severe periodontitis is estimated to affect $5 \%-20 \%$ of adults in both developed and developing countries. Moreover, gingivitis is ubiquitous in adults, and its signs are prevalent as well among most children and adolescents [1]. In its early stages, periodontitis begins with gingival inflammation and in its later stages may progress to tooth mobility, pathological migration and tooth loss, causing chewing and speech dysfunction, aesthetic and psychological problems and impaired quality of life [2].

Since prevention and control of oral diseases are influenced by personal behaviour, several theories and models are useful in interpreting behaviour changes. The knowledge, attitudes and practice model is one of the models explaining how new knowledge acquisition leads to improved attitudes and facilitates behaviour change [3]. Based on this model, what people know and believe about periodontal health and disease is important in order to establish prevention practices [4].

In different regions of Asia, including developed and developing countries, studies using the community periodontal index (CPI) showed that more than $60 \%$ of adults had CPI scores of 2-4, indicating detection of calculus during probing and pocket depths of $4 \mathrm{~mm}$ and more [5]. In the Islamic Republic of Iran, this score is prevalent in about $70 \%$ of young adults [6] and $93 \%$ of the middle-aged population [7]. Nevertheless, studies assessing the knowledge of and attitudes toward oral and periodontal health in the Iranian population are scarce. The relevant studies have been limited to a selected subgroup of adults $[8,9]$. The present study was carried out to fill this gap and to assess the periodontal knowledge and attitudes toward periodontal health of an adult population residing in Tehran.

\section{Methods}

\section{Study design and sample}

The study used a cross-sectional, population-based, interviewer-assisted survey from February to March 2011 among subjects between ages 18 and 50 years living in Tehran. These age groups included about $80 \%$ of the whole adult population of the city [10]. To select a representative sample, we applied stratified, multistage, random-area sampling. The 22 districts of Tehran (based on an administrative map) were considered as strata. Tehran, with a total population of 7 million inside the city, includes 22 municipal districts as follows; North (2), East (4), West (5), Centre (5), and South (6), with the southern and central areas having the highest population density [11].

The sample in each stratum was weighted according to the proportion of the population of the district compared with that of the whole city. Within each stratum, areas were selected randomly as clusters that were equivalent to 80 areas in total. Then in each area, 1 block (around 200 buildings) was identified randomly. 10 houses in each block were selected, considering that each household within the black had the same probability to be sampled. The sex and age characteristics of the sample in each block were matched with the population pattern of that block. To reach the calculated sample size in each block, 1 person was chosen in the selected household. If more than one person was found with the same characteristics in the household another was chosen randomly [12]. If the household did not contain such a person, the interviewers moved to the adjacent house. In case that sample was not obtained in a block, the interviewers moved to the next block to the south-east.

A sample size of 800 was estimated using a sample size calculation for estimating a single proportion $(\alpha=0.05$, prevalence of adequate periodontal knowledge $=0.2$ from the pilot study, and design effect $=2$ ).

\section{Questionnaire development}

A 19-item questionnaire based on previous studies [9,13-17] was developed to assess periodontal knowledge and attitudes. In the knowledge section, 2 items focused on gingival appearance, 3 items addressed causes and outcomes of periodontal disease, 1 item was related to the impact of systemic disease on the progression of periodontal conditions, and 4 items were associated with prevention. In the attitudes section there were 9 statements about periodontal health and disease.

The questionnaire items were initially revised by an expert panel. The face validity of the questionnaire was subsequently assessed with the aid of lay people's opinions. Content validity was then evaluated by the expert panel regarding the relevancy, clarity, simplicity and necessity of the questionnaire's items. The items were corrected, substituted or deleted if necessary. Then the scale content validity index (0.92) and the content validity ratio $(0.87)$ were calculated and assessed as acceptable [18]. In the pilot study, the external reliability, reported as percentage agreement by test-retest, was $>70 \%$ for all questions. To assess internal consistency, Cronbach alpha was calculated and found to be $67 \%$.

\section{Survey interviews}

A structured face-to-face interview based on the questionnaire was selected as the method of choice. The randomly selected participants were interviewed individually at their homes [19]. When data collection of each district was finished, the data of a subgroup of participants were chosen randomly and reviewed in order to ensure the accuracy of the recorded information.

Eighteen (18) trained interviewers from a professional agency (Iranian Students' Polling Agency) carried out data collection. In order to ensure uniformity in data collection and avoid inter-interviewer variability, detailed information 
regarding the process of interviewing and ethical considerations were delivered by the main researcher in a 2 -hour meeting in which interviewers received relevant guidelines on the ethical issues, the questionnaire and the interview [12].

Participation in the present survey was voluntary, and data were collected anonymously. Before the interviews, participants gave their informed consent. The research was approved by the Tehran University of Medical Science ethics committee.

\section{Data treatment and statistical analysis}

The responses to the questions about periodontal knowledge were scored as true (score 1 ) and false (score 0 ), and a sum score derived from 10 questions (range: 0-10) was calculated for each participant. The statements associated with periodontal attitude had 5-response categories: strongly agree, agree, no opinion, disagree and strongly disagree. For analysis, we combined the categories strongly agree and agree to yield the measure of agreement, and the categories no opinion, disagree and strongly disagree to yield the measure of disagreement. Positive attitude was the percentage of agree responses in the 1st and the 9th statements regarding periodontal health and disagree responses in the other statements. A sum score of periodontal attitude was calculated for each subject, considering positive attitude (score 1), and negative attitude (score 0 ) for each statement, with higher scores indicating a more positive attitude [20]. The average living area in square metres per person as of the participants was assessed as a proxy indicator of economic status of the participants (range: 6-175 $\mathrm{m}^{2}$ /person), based on the distribution of the data, categorized into 3 levels: low (< 23.8), moderate (23.8-36.7), and high $(\geq 36.7)[21]$.

The data were analysed with SPSS, version 16. For comparison of knowledge and attitude with sociodemographic variables, a $t$-test and one-way analyses of variance were employed. Significance level was set at $P<0.05$. Linear regression was fitted to the data to assess the effect of independent variables such as knowledge score and sociodemographic variables on attitude. According to the knowledge, attitudes and practice model, we considered attitude as a dependent variable in the regression model $[3,22]$.

\section{Results}

The background characteristics of the 791 participants are presented in Table 1. The mean age was 32.6 years and $50.3 \%$ were male.

Responses to the knowledge questions are shown on Table 2. The lowest level of knowledge was related to the definition of dental plaque (11.7\%) and its role as the cause of gum disease (13.8\%), and tooth mobility as the outcome of gum disease (27.0\%). Red gingiva as an early sign of periodontal disease, and diabetes as an effective systemic disease related to progression of the disease, were pointed out correctly by nearly $40 \%$ of the respondents. A majority of the participants considered gum disease as preventable, and believed in the efficacy of preventive measures.

The respondents' attitudes toward periodontal health and disease varied greatly, as shown by their answers to the attitude statements (Figure 1). Generally, the participants showed a positive attitude towards periodontal health, including its impact on their work and

\begin{tabular}{|c|c|c|}
\hline Variable & No. & $\%^{c}$ \\
\hline \multicolumn{3}{|l|}{ Sex } \\
\hline Male & 398 & 50.3 \\
\hline Female & 393 & 49.7 \\
\hline \multicolumn{3}{|l|}{ Age group (years) } \\
\hline $18-24$ & 216 & 27.3 \\
\hline $25-34$ & 257 & 32.5 \\
\hline $35-44$ & 192 & 24.3 \\
\hline$\geq 45$ & 126 & 15.9 \\
\hline \multicolumn{3}{|l|}{ Education } \\
\hline Illiterate/primary ${ }^{a}$ & 126 & 16.0 \\
\hline High school & 336 & 42.6 \\
\hline University & 327 & 41.4 \\
\hline \multicolumn{3}{|l|}{ Marital status } \\
\hline Married & 276 & 35.2 \\
\hline Single & 507 & 64.8 \\
\hline \multicolumn{3}{|l|}{ Employment status } \\
\hline Employed & 384 & 48.9 \\
\hline Unemployed & 62 & 7.9 \\
\hline Student & 99 & 12.6 \\
\hline Homemaker & 224 & 28.5 \\
\hline Other & 16 & 2.1 \\
\hline \multicolumn{3}{|l|}{ Economic status $^{b}$} \\
\hline Low & 227 & 33.4 \\
\hline Moderate & 223 & 32.8 \\
\hline High & 230 & 33.8 \\
\hline
\end{tabular}

alliterate/primary: $<9$ years of education; ${ }^{b}$ Based on average living area per person: low ( $<23.8 \mathrm{~m}^{2} /$ person), moderate (23.8-36.7 $\mathrm{m}^{2} /$ person), and high ( $\geq 36.7 \mathrm{~m}^{2} /$ person); c Percentages were calculated out of total for the category (data missing in some categories). 


\begin{tabular}{|c|c|c|c|c|c|}
\hline \multirow[t]{2}{*}{ Question (correct answer) } & \multirow{2}{*}{$\begin{array}{l}\text { Total } \\
\text { No. }\end{array}$} & \multicolumn{2}{|c|}{ True } & \multicolumn{2}{|c|}{ False } \\
\hline & & No. & $\%$ & No. & $\%$ \\
\hline How would you describe healthy gums? (pink and firm) & 784 & 470 & 59.9 & 314 & 40.1 \\
\hline $\begin{array}{l}\text { What is dental plaque? (soft colourless and sticky } \\
\text { deposits containing microbe and food debris) }\end{array}$ & 788 & 92 & 11.7 & 696 & 88.3 \\
\hline What causes gum disease? (dental plaque) & 784 & 108 & 13.8 & 676 & 86.2 \\
\hline Which one is an early sign of gum disease? (red gingiva) & 782 & 312 & 39.9 & 470 & 60.1 \\
\hline $\begin{array}{l}\text { Which one is the outcome of progressed gum disease? } \\
\text { (tooth mobility) }\end{array}$ & 785 & 212 & 27.0 & 573 & 73.0 \\
\hline $\begin{array}{l}\text { Which of the following systemic diseases affects } \\
\text { progression of gum disease? (diabetes) }\end{array}$ & 782 & 280 & 35.8 & 502 & 64.2 \\
\hline Mostly gum disease is preventable & 791 & 703 & 88.9 & 88 & 11.1 \\
\hline $\begin{array}{l}\text { Twice a day tooth brushing together with flossing is } \\
\text { efficient in preventing gum disease }\end{array}$ & 788 & 721 & 91.5 & 67 & 8.5 \\
\hline Regular dental visits can prevent gum disease & 788 & 731 & 92.8 & 57 & 7.2 \\
\hline Avoiding smoking prevents gum disease & 790 & 713 & 90.3 & 77 & 9.7 \\
\hline
\end{tabular}

social relations, and towards the importance of oral diseases among other systemic diseases. On the other hand, a high percentage of the respondents saw tooth brushing with salt as a useful measure for prevention of gum disease and considered scaling as harmful for gum health. In addition, a minority considered that their teeth did not seem normal any longer because of gum disease.
Table 3 presents the mean periodontal disease knowledge scores and attitude scores in relation to the sociodemographic background variables sex, age group, education and economic status. Women had significantly higher mean knowledge scores than did men $(P=0.011)$, and more highly educated respondents had higher knowledge and attitude scores than did those less well educated $(P<0.001)$. Participants with high economic status had the highest periodontal disease knowledge $(P=$ $0.015)$ and attitude $(P=0.006)$ scores.

In the linear regression model, high periodontal disease knowledge scores and university level of education were only the variables that were significantly associated with positive attitudes toward periodontal health $(P<0.05)($ Table 4$)$.

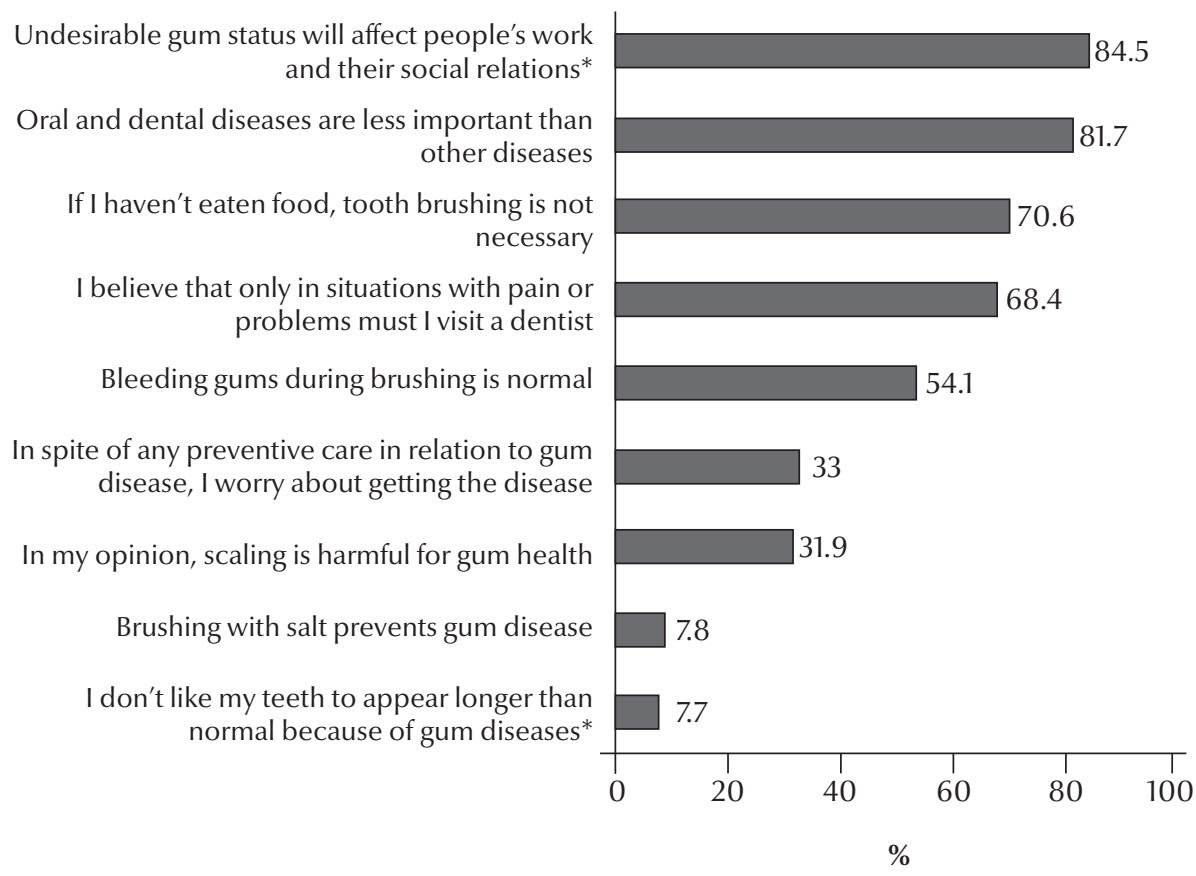

Figure 1 Positive attitudes towards statements regarding periodontal disease $(n=791)\left({ }^{*}\right.$ Completely agree/agree $)$ 


\begin{tabular}{|c|c|c|c|c|}
\hline \multirow[t]{2}{*}{ Variable } & \multicolumn{2}{|c|}{ Knowledge score } & \multicolumn{2}{|c|}{ Attitude score } \\
\hline & Mean (SD) & $P$-value & Mean (SD) & $P$-value \\
\hline \multicolumn{5}{|l|}{ Sex } \\
\hline Male & $5.40(1.61)$ & $0.011^{\mathrm{a}}$ & $4.97(1.76)$ & $0.106^{\mathrm{a}}$ \\
\hline Female & $5.70(1.67)$ & & $5.18(1.70)$ & \\
\hline \multicolumn{5}{|l|}{ Age group (years) } \\
\hline $18-24$ & $5.47(1.70)$ & $0.558^{\mathrm{b}}$ & $5.03(1.64)$ & $0.625^{b}$ \\
\hline $25-34$ & $5.59(1.55)$ & & $5.09(1.75)$ & \\
\hline $35-44$ & $5.65(1.69)$ & & $5.20(1.84)$ & \\
\hline$\geq 45$ & $5.43(1.67)$ & & $4.95(1.65)$ & \\
\hline \multicolumn{5}{|l|}{ Education } \\
\hline Illiterate/primary & $4.76(1.62)$ & $<0.001^{\mathrm{b}}$ & $4.48(1.83)$ & $<0.001^{\mathrm{b}}$ \\
\hline High school & $5.45(1.57)$ & & $5.02(1.64)$ & \\
\hline University & $5.96(1.60)$ & & $5.36(1.72)$ & \\
\hline \multicolumn{5}{|l|}{ Economic status $^{c}$} \\
\hline Low & $5.34(1.48)$ & $0.015^{b}$ & $4.77(1.85)$ & $0.006^{b}$ \\
\hline Moderate & $5.46(1.86)$ & & $5.08(1.69)$ & \\
\hline High & $5.78(1.58)$ & & $5.30(1.67)$ & \\
\hline
\end{tabular}

${ }^{a}$ t-test; ${ }^{b}$ Analysis of variance; ${ }^{c}$ Based on average living area per person: low ( $<23.8 \mathrm{~m}^{2} /$ person), moderate (23.8-36.7 $\mathrm{m}^{2} /$ person), and high $\left(\geq 36.7 \mathrm{~m}^{2} /\right.$ person). $S D=$ standard deviation .

\section{Discussion}

Our study demonstrated poor knowledge of periodontal disease, including its aetiology, signs, and outcomes, but an overall positive attitude towards periodontal health among Iranian adults. In general, higher knowledge related to periodontal health and disease was significantly associated with positive attitudes.

\section{Status of periodontal knowledge}

The majority of the participants had poor knowledge regarding the aetiology of periodontal disease, including the role of dental plaque. This finding is in line with earlier findings regarding the causes of periodontal disease $[9,14,23]$. Lin et al. showed that a high percentage of Chinese adults were unaware of the causes of oral diseases, including dental caries and gum disease [17]. In that

\begin{tabular}{|c|c|c|c|c|}
\hline Variable & $B$-value & $95 \% \mathrm{Cl}$ & $t$-value & $P$-value \\
\hline Knowledge sum score & 0.36 & 0.28 to 0.44 & 8.84 & $<0.001$ \\
\hline \multicolumn{5}{|l|}{ Sex } \\
\hline Male & ref. & & & \\
\hline Female & 0.09 & -0.15 to 0.35 & 0.74 & 0.454 \\
\hline \multicolumn{5}{|l|}{ Age (years) } \\
\hline $18-24$ & ref. & & & \\
\hline $25-34$ & 0.06 & -0.26 to 0.40 & 0.39 & 0.691 \\
\hline $35-44$ & 0.21 & -0.15 to 0.57 & 1.13 & 0.255 \\
\hline$\geq 45$ & 0.15 & -0.26 to 0.57 & 0.71 & 0.475 \\
\hline \multicolumn{5}{|l|}{ Education } \\
\hline Illiterate/primary & ref. & & & \\
\hline High school & 0.27 & -0.11 to 0.66 & 1.37 & 0.170 \\
\hline University & 0.51 & 0.09 to 0.93 & 2.39 & 0.017 \\
\hline Economic status $\left(m^{2} /\right.$ person $\left.^{a}\right)$ & 0.001 & -0.003 to 0.005 & 0.46 & 0.639 \\
\hline
\end{tabular}

${ }^{a}$ Based on average living area in square metres per person.

$\mathrm{Cl}=$ confidence interval; ref. = reference group. 
survey, few were able to identify dental plaque as one of the causes of gum disease. A similar lack of knowledge as to the role of dental plaque in gum disease has emerged among adults in Jordan and in the Islamic Republic of Iran $[9,23]$. Generally, public awareness of gum disease and particularly the role of dental plaque in relation to periodontal disease is weak, presumably due to inadequate health education concerning these conditions. However, most of the study participants had a good level of knowledge regarding the role of oral hygiene in preventing gum disease, a finding which was reported elsewhere $[9,14,23]$.

\section{Attitudes toward periodontal health and disease}

Attitudes among our participants regarding the importance of oral and dental diseases in comparison with other systemic diseases, as well as the impact of gum disease on occupational and social relationships, were largely positive. They also showed positive views toward preventive practices, including oral hygiene and regular check-ups. They commonly believed that gum disease may occur even despite preventive care. This may demonstrate that they considered gum disease as not fully preventable.

The participants had some misconceptions regarding particular topics, including the impact of the application of salt and of dental scaling on gum health. Use of salt in any form including salt water or salt powder to clean teeth is common in Islamic Republic of Iran. Application of salt water to rinse the mouth is a widespread method believed to cure gingival problems such as gum bleeding or gum looseness [9]. In our study, the majority of participants considered tooth brushing with salt as an appropriate method to prevent gum disease, regardless of the possible disadvantages of this method such as damage to the gums and tooth abrasion [24]. In addition, the study found negative attitudes toward dental scaling among Iranian adults. They considered scaling harmful for gum health, as did respondents in a study conducted in Hong Kong [25].

\section{Relationship between knowledge/attitude and background}

In our study, the periodontal knowledge score was significantly higher among women, a finding also reported among Japanese young adults [26]. This implies that women value dental health more than do men and are more willing to improve their health status and receive relevant information [27]. On the other hand, no clear relationship between the periodontal knowledge score and age was evident, which is in line with the findings of a study from Germany [14], but in contrast to other findings in Jordan [15] and in Sweden [16].

In our study, higher education was related to a higher knowledge score; a similar finding emerged in a Swedish study among adults [16]. One study demonstrating elderly adults' knowledge of and attitudes towards oral health has shown a similar association between oral health knowledge and level of education [17].

In relation to attitudes towards periodontal health among our participants, those with a university education had a better attitude than did those with lower educational levels. Neither economic status nor sex of participants was associated with attitudes towards periodontal health. However, Furuta et al. demonstrated that Japanese women appreciated dental visits to prevent gingivitis more than did men [28].

\section{Strengths and weaknesses of the study}

The knowledge, attitudes and practice model served as our theoretical framework for development of the survey tool. This model explains changesin attitude through knowledge improvement and, despite the weaknesses attributed to it, the model is still useful as the theoretical framework for various dental health education interventions [3]. Because we had no access to a standard questionnaire to assess periodontal knowledge and attitudes, a researcher-created instrument allowed collection of information after tests of its validity and reliability. Our stratified, multistage, random sampling method covered all 22 districts of Tehran to increase the representativeness of the sample. In order to increase the response rate, the participants were interviewed instead of being asked to fill in the questionnaires themselves [29]. To reduce information bias, all interviewers were calibrated, and the interview process was supervised. However, their presence and any explanations by the interviewers might have impacted the participants' answers. In addition, positive attitudes in this study were measured in some statements by use of "disagree" responses, which was also the system used by Lin et al. [17].

\section{Conclusions}

Our results showed poor periodontal knowledge alongside a generally positive attitude towards and great appreciation of periodontal health among Iranian adults. Health education programmes should place more emphasis on causes and manifestations of periodontal disease.

\section{Acknowledgements}

The authors express their thanks to Dr Simin Z. Mohebbi for her assistance in developing the questionnaire.

Funding: This study was supported by Tehran University of Medical Science and Health Services grant no. 90-0169-12892.

Competing interests: None declared. 


\section{References}

1. Petersen PE et al. The global burden of oral diseases and risks to oral health. Bulletin of the World Health Organization, 2005, 83:661-669.

2. Jin LJ et al. Global oral health inequalities task group-periodontal disease. Advances in Dental Research, 2011, 23:221-226.

3. Health education: theoretical concepts, effective strategies and core competencies: a foundation document to guide capacity development of health educators. Cairo, World Health Organization Regional Office for the Eastern Mediterranean, 2012. (http://applications.emro.who.int/dsaf/EMRPUB_2012_ EN_1362.pdf, accessed 11 January 2014).

4. Schwarz E, Lo EC. Dental health knowledge and attitudes among the middle-aged and the elderly in Hong Kong. Community Dentistry and Oral Epidemiology, 1994, 22:358-363.

5. Corbet EF, Zee KY, Lo EC. Periodontal diseases in Asia and Oceania. Periodontology 2000, 2002, 29:122-152.

6. Hessari $\mathrm{H}$ et al. Oral health and treatment needs among 18-year-old Iranians. Medical Principles and Practice, 2008, 17:302-307.

7. Hessari $\mathrm{H}$ et al. Oral health among 35- to 44-year-old Iranians. Medical Principles and Practice, 2007, 16:280-285.

8. Bakhshandeh $\mathrm{S}$ et al. Oral self-care and use of dental services among adults with diabetes mellitus. Oral Health and Preventive Dentistry, 2008, 6:279-286.

9. Gholami M, Pakdaman A, Virtanen Jl. Common perceptions of periodontal health and illness among adults: a qualitative study. ISRN Dentistry, 2012, 2012. doi: 10.5402/2012/671879.

10. [Iran statistical yearbook 1385]. Tehran, Statistical Centre of Iran, Management and Planning Organization, 2006-07 [in Farsi].

11. Cities with a population of 100,000 and more. Publication database. Tehran, Statistical Centre of Iran, 2006 [online database] (http://amar.sci.org.ir/Detail.aspx?Ln=E\&no=98494\&S=SS, accessed 15 May 2013).

12. Naghibi Sistani MM et al. Determinants of oral health: does oral health literacy matter? ISRN Dentistry, 2013. doi:10.1155/2013/249591.

13. Chen $\mathrm{M}$ et al. Comparing oral health care systems, a second international collaborative study. Geneva, World Health Organization, 1997.

14. Deinzer R et al. More to learn about: periodontitis-related knowledge and its relationship with periodontal health behaviour. Journal of Clinical Periodontology, 2009, 36:756764.

15. El-Qaderi SS, Quteish Ta'ani D. Assessment of periodontal knowledge and periodontal status of an adult population in
Jordan. International Journal of Dental Hygiene, 2004, 2:132136.

16. Mårtensson C et al. Factors behind change in knowledge after a mass media campaign targeting periodontitis. International Journal of Dental Hygiene, 2006, 4:8-14.

17. Lin $\mathrm{HC}$ et al. Oral health knowledge, attitudes, and practices of Chinese adults. Journal of Dental Research, 2001, 80:1466-1470.

18. Lynn MR. Determination and quantification of content validity. Nursing Research, 1986, 35:382-386.

19. Nedjat $\mathrm{S}$ et al. Psychometric properties of the Iranian interview-administered version of the World Health Organization's Quality of Life Questionnaire (WHOQOL-BREF): a populationbased study. BMC Health Services Research, 2008, 8:61.

20. Buunk-Werkhoven YA, Dijkstra A, van der Schans CP. Determinants of oral hygiene behavior: a study based on the theory of planned behavior. Community Dentistry and Oral Epidemiology, 2011, 39:250-259.

21. Donyavi $\mathrm{T}$ et al. Socioeconomic status and mortality after acute myocardial infarction: a study from Iran. International Journal for Equity in Health, 2011, 10:9.

22. Khami MR et al. Knowledge and attitude of Iranian dental school educators towards prevention. Oral Health and Preventive Dentistry, 2007, 5:181-186.

23. Taani DQ. Periodontal awareness and knowledge, and pattern of dental attendance among adults in Jordan. International Dental Journal, 2002, 52:94-98.

24. Yaacob HB, Park AW. Dental abrasion pattern in a selected group of Malaysians. Journal of Nihon University School of Dentistry, 1990, 32:175-180.

25. Young C. A survey on misunderstanding of dental scaling in Hong Kong. International Journal of Dental Hygiene, 2008, 6:25-36.

26. Tada A, Hanada N. Sexual differences in oral health behaviour and factors associated with oral health behaviour in Japanese young adults. Public Health, 2004, 118:104-109.

27. Galdas PM, Cheater F, Marshall P. Men and health help-seeking behaviour: literature review. Journal of Advanced Nursing, 2005, 49:616-623.

28. Furuta $M$ et al. Sex differences in gingivitis relate to interaction of oral health behaviors in young people. Journal of Periodontology, 2011, 82:558-565.

29. De Leeuw ED. To mix or not to mix data collection modes in surveys. Journal of Official Statistics, 2005, 21:233-255. 